\title{
Experimental Study on Spontaneous Imbibition Characteristics of Fracturing Fluid at Cores from Different Layers in Fuling Shale Gas Reservoir
}

\author{
Sidong Fang $\mathbb{D}^{1,2}$ Jing Sun $\mathbb{D}^{1,3}$ DeHua Liu $\mathbb{D}^{1,3}$ Zhiyuan Yao $\mathbb{D}^{1,3}$ and Bin Nie $\mathbb{D}^{1,3}$ \\ ${ }^{1}$ State Key Laboratory of Shale Oil and Gas Enrichment Mechanisms and Effective Development, Beijing, China 100089 \\ ${ }^{2}$ Sinopec Petroleum Exploration and Development Research Institute, Beijing, China 100089 \\ ${ }^{3}$ College of Petroleum Engineering, Yangtze University, Wuhan, China 430100
}

Correspondence should be addressed to Jing Sun; 77220250@qq.com

Received 21 May 2021; Accepted 9 August 2021; Published 15 September 2021

Academic Editor: Yonghui Wu

Copyright ( 2021 Sidong Fang et al. This is an open access article distributed under the Creative Commons Attribution License, which permits unrestricted use, distribution, and reproduction in any medium, provided the original work is properly cited.

\begin{abstract}
With low porosity and low permeability, shale reservoirs cannot be mined economically without large-scale hydraulic fracturing operation. However, abundant fracturing fluid will enter the reservoirs during the process of fracture. Nevertheless, there have not been specific research findings on the imbibition law of Fuling shale gas reservoir in China. In this study, an imbibition experiment was carried out on the shale core of Jiaoshiba block of Fuling shale gas reservoir to learn spontaneous imbibition characteristic of Fuling shale gas reservoir. Based on the experimental results, the imbibition process of Fuling shale gas reservoir fracturing fluid is divided into two stages. During the first stage, i.e., the former 30 hours, imbibition velocity is high, with the cumulative imbibition occupying more than $70 \%$ of the total imbibition; during the second stage, i.e., the latter 30 hours, the imbibition velocity substantially drops towards balance. There is a typical power function relationship between the average imbibition velocity and imbibition time, and this function relationship runs throughout the whole imbibition process. Nonetheless, the imbibition process of shale core cannot be described directly by the Handy equation. The imbibition velocity is closely related to clay mineral content and pore structure characteristics of shale core. The higher the clay mineral content, the higher the imbibition velocity. According to the relationship between the average imbibition velocity and imbibition time, we derived the estimation equation of fracture area formed by fractured shale gas well to estimate the fracture scale formed by shale gas well fracturing.
\end{abstract}

\section{Introduction}

With the economic development worldwide, shale gas, as a new type of clean energy, has gradually set off a revolutionary wave of exploitation in China. Sichuan Basin in China is rich in shale gas resources, with the reserves of geological resources being $40.02 \times 10^{12} \mathrm{~m}^{3}$, indicating great potential for exploration and development [1]. With special geological characteristics, the shale gas reservoir can only be put into production by large-scale hydraulic fracturing conducted through horizontal well. Fractures can expand the migration channel of shale gas and improve the seepage capacity of shale [2]. However, during the large-scale hydraulic fracturing conducted through the horizontal well, a large amount of fracturing fluid will enter the reservoir. Developed with nano-micropores, the shale reservoir has a high clay mineral content and a strong capillary force, with the matrix reservoir playing a strong role in imbibing fracturing fluid. The imbibition of matrix-fracture system in the shale reservoir will affect the gas production of shale gas wells. Under the action of imbibition, water saturation inside the reservoir tends to be relatively high, resulting in the decline of matrix permeability and even the phenomenon of "water lock," which seriously affects the effective production of oil and gas in the reservoir [3]. Penny et al. considered that the invasion of fracturing fluid will damage the reservoir and cause water lock in shale gas wells [4]. Through conducting abundant studies, Sherman and Holditch [5], Bazin et al. [6], and Cheng [7] have realized that the reservoir fluid introduced in the process of fracturing will greatly affect the physical 
TABLE 1: Selected rock samples.

Samples

TABLE 2: Characteristic parameters of rock samples.

\begin{tabular}{lcccccccc}
\hline Samples & Length $(\mathrm{cm})$ & Diameter $(\mathrm{cm})$ & Cross-sectional area $\left(\mathrm{cm}^{2}\right)$ & Volume $\left(\mathrm{cm}^{3}\right)$ & Porosity $(\%)$ & TOC $(\%)$ & Clay content $(\%)$ & Layer \\
\hline $1 \#$ & 3.71 & 2.51 & 4.95 & 18.35 & 5.63 & 5.37 & 26.1 & Lower \\
$2 \#$ & 3 & 2.51 & 4.95 & 14.72 & 4.38 & 4.12 & 27.6 & Lower \\
$3 \#$ & 3.552 & 2.51 & 4.95 & 17.57 & 5.82 & 1.26 & 61.6 & Upper \\
$4 \#$ & 3.5 & 2.51 & 4.95 & 17.31 & 4.17 & 0.64 & 58.8 & Upper \\
\hline
\end{tabular}

properties of the reservoir, thereby damaging the reservoir. However, according to Lijun et al. [8], Xiaozhe and Changsha [9], Shicheng et al. [10], and Ghanbari and Dehghanpour [11], the amount of fracturing fluid retained in the gas reservoir may not only damage the gas reservoir but also induce fractures to play a positive role in gas transfer. Hence, unconventional reservoir's imbibition of fracturing fluid has always been a key problem in the development of shale reservoirs.

With regard to imbibition characteristics, relevant researches have been carried out and corresponding models of calculating the imbibition velocity have been established. In 1921, Washburn set up a single capillary imbibition model according to Hagen-Poiseuille's law, which laid a foundation for exploring the imbibition law [12]. According to the similarity criterion, Mattax and Kyte [13] proposed to study imbibition by means of indoor experiment, obtaining the expression formula of imbibition velocity. In 1960, assuming that the water imbibition process was a pistonlike displacement process, Handy established a water imbibition model of gas saturated core [14]. After that, Gupta and Civan [15], Li and Horne [16], and Mason et al. [17] came up with the modified model about imbibition.

However, there are currently not many research findings on the imbibition law of shale gas reservoirs in China, and the imbibition law of Fuling shale gas reservoirs in China has not been clearly understood. On this basis, we conducted imbibition experiments on 4 cores from different layers of the Fuling shale gas field in China. The experimental results show that reservoir cores from different layers have different imbibition characteristics. Based on the experimental results, an imbibition model reflecting characteristics of Fuling shale gas reservoir was established. The study shows that it is improper to characterize the imbibition velocity of shale gas reservoirs in China using the Handy model, so the model remains to be modified. Furthermore, we deduced the method of estimating fracture surface of the fractured well to preliminarily estimate the fracture area produced by the shale gas well. The research results gained in this study can provide effective guidance for optimizing the design of shale fractured horizontal wells and increasing the output of shale gas wells in China.

\section{Imbibition Experiments}

2.1. Materials. The rock samples used in the experiment were extracted from the first section of Wufeng-Longmaxi Formation in Phase-I Production and Construction Area in Jiaoshiba, Fuling, China. The rock samples were longitudinally divided into 9 layers. Among them, 1-5 layers are the lower reservoir and 6-9 layers are the upper reservoir, with the lower 5 layers being the main target strata. The 4 rock samples were numbered $1 \#, 2 \#, 3 \#$, and $4 \#$, respectively. $1 \#$ and 2\# samples were collected from the lower reservoir of Wufeng-Longmaxi Formation, with the TOC content being $40-50 \%$ and the clay mineral content being about $26 \%$. 3\# and $4 \#$ samples were collected from the upper reservoir of the Wufeng-Longmaxi Formation, with a relatively low TOC content of $0.64-1.78 \%$ and a high clay mineral content of $38.4-58.8 \%$. Table 1 shows the selected rock samples, and Table 2 shows the characteristic parameters of rock samples. 


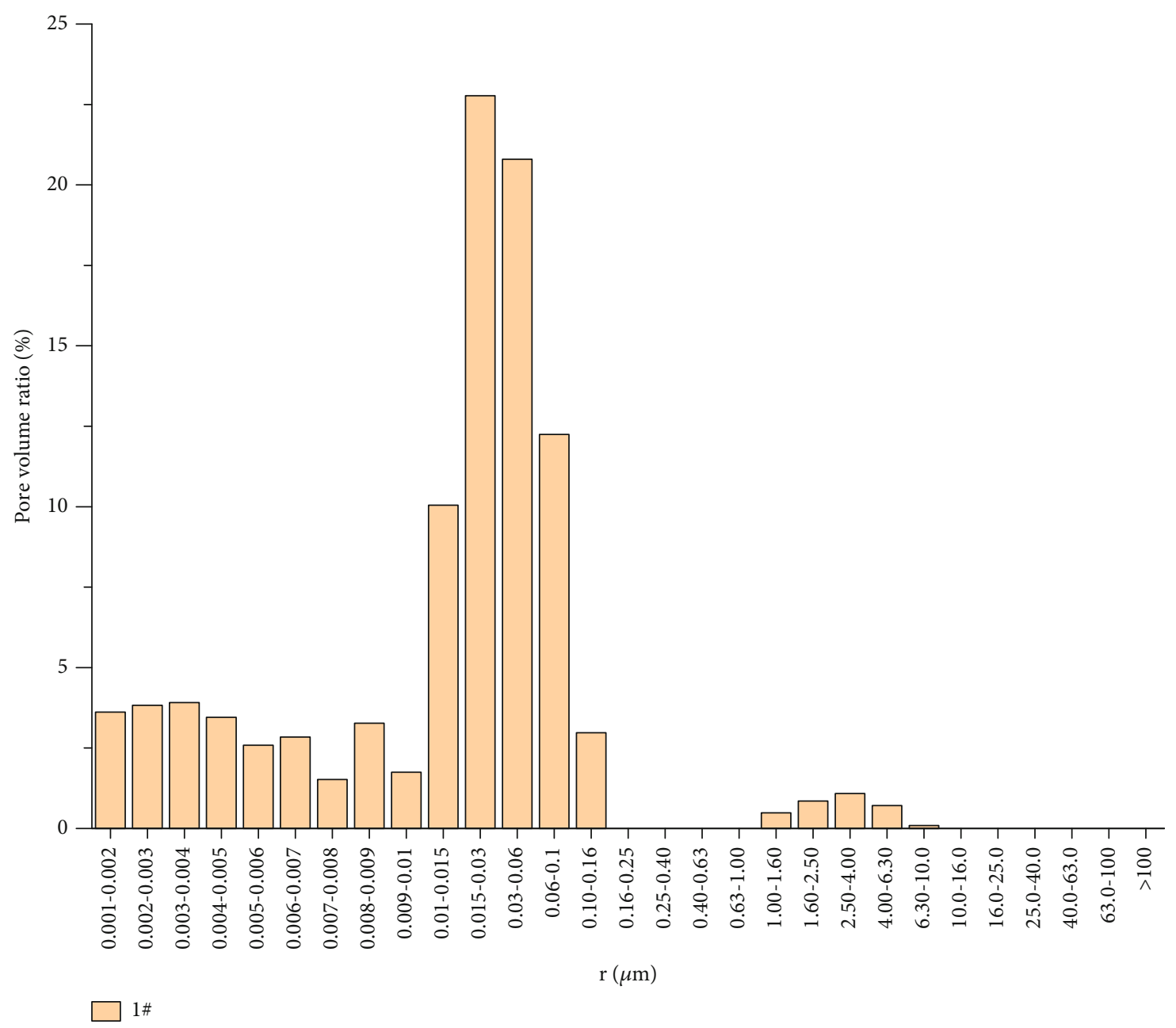

FIGURE 1: Distribution characteristics of pore structure of 1\# shale core sample.

According to the fracturing fluid formula at the construction site, the fracturing fluid used in the experiment was prepared with $99.5 \%$ water and $0.5 \%$ additives.

The magnetic resonance imaging (MRI) system was used to test the distribution characteristics of pore structure of each shale core sample, as shown in Figures 1-4.

Based on the above schematic diagrams of distribution characteristics of pore structure and the definition given by the International Union of Pure and Applied Chemistry (IUPAC) [18], the pores of $1 \#$ and $2 \#$ rock samples were dominated by mesopores and macropores with a diameter of larger than $10 \mathrm{~nm}$, with the proportion of pore volume larger than $10 \mathrm{~nm}$ reaching more than $50 \%$; $3 \#$ and $4 \#$ samples were collected from the lower reservoir of the first section of the Wufeng-Longmaxi Formation. The pores of 3\# and 4\# samples were mainly micropores with a diameter of less than $10 \mathrm{~nm}$, and the volume of pores with a diameter of less than $10 \mathrm{~nm}$ occupied a proportion of over $80 \%$. 3\# and 4\# samples were extracted from the upper reservoir of the Wufeng-Longmaxi Formation in Phase-I Production and Construction Area in Jiaoshiba, Fuling, China.

2.2. Experimental Setup and Procedure. This experiment mainly simulated the spontaneous imbibition of fracturing fluid in shale reservoir. The so-called spontaneous imbibition refers to the process during which the porous medium spontaneously absorbs some wet liquid under the capillary force. Figure 5 shows the imbibition experimental facility. First of all, the rock samples were dried at $120^{\circ} \mathrm{C}$ for 24 hours to determine the dry weight of the samples. After that, the side of the samples was wrapped with Teflon tape and then placed in the imbibition experimental facility as shown in Figure 6, with the bottom surface of the samples being contacted with the level of fracturing fluid in the container. Due to pore density of the shale core and abundant clay minerals in the shale core, $99.5 \%$ of the fracturing fluid is water. After contacting the fracturing fluid, the bottom of the rock samples would produce a strong capillary force to suck the fracturing fluid into the porous medium of the shale core. This experiment was performed to simulate the imbibition of fracturing fluid from the fracture-matrix system during the fracturing of horizontal shale gas well. Once the imbibition experiment was started, the weight of the core was weighed and recorded at regular intervals until the weight of the samples remained almost constant. According to the above method, the imbibition experiments were carried out on 4 rock samples collected from Phase-I Production and Construction Area in Jiaoshiba, Fuling, China. 


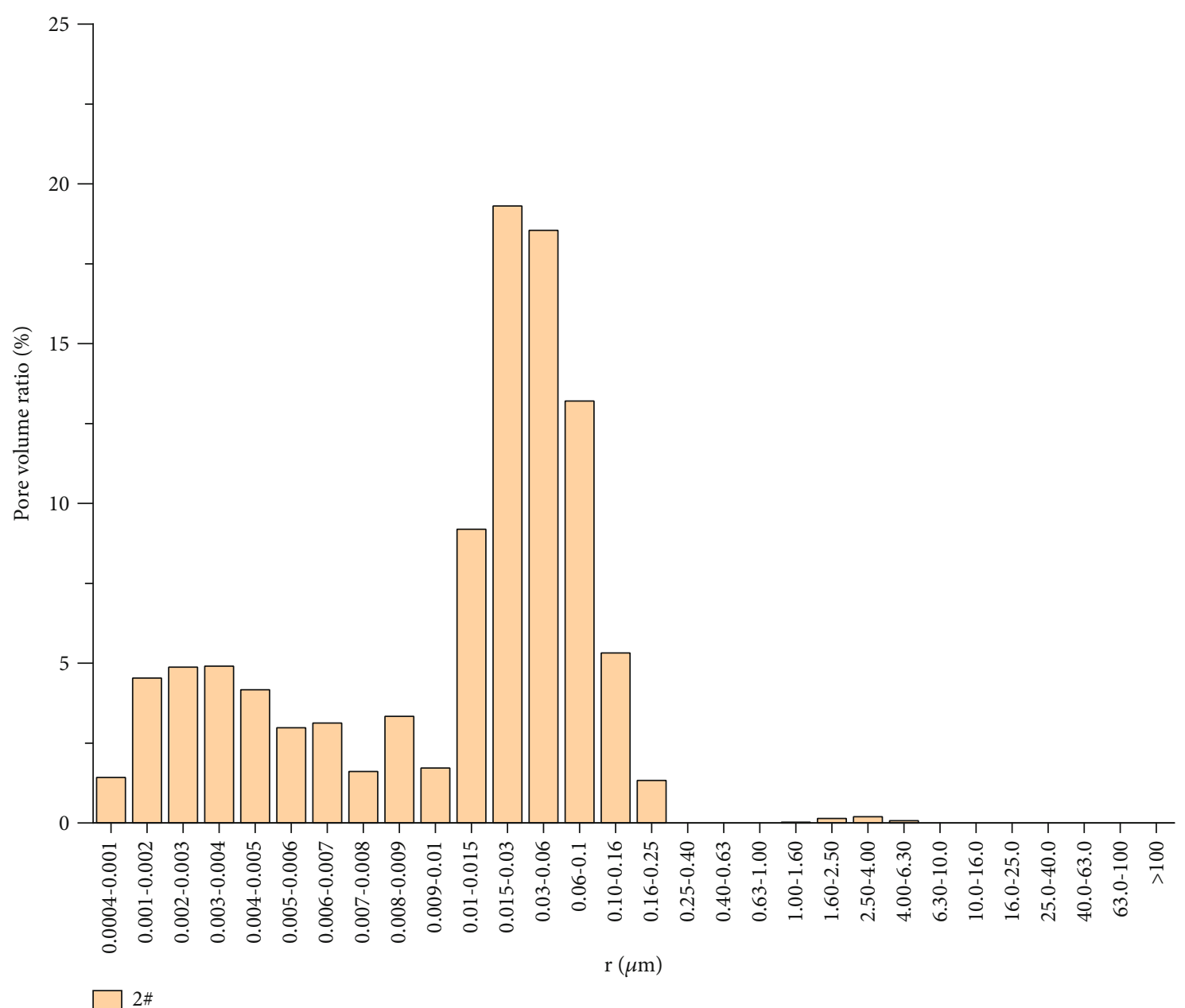

Figure 2: Distribution characteristics of pore structure of 2\# shale core sample.

\subsection{Experimental Results}

2.3.1. Imbibition Capabilities of Cores from Different Layers. According to the above experimental steps, the core weight of each rock sample was recorded for every 2 hours of imbibition, and the experiment lasted for 114 hours. By subtracting the dry weight of rocks samples from the core weight measured under different imbibition time, we obtained the amount of fracturing fluid volume absorbed by the rock samples under different imbibition time. By calculating the imbibition of $1 \#, 2 \#, 3 \#$, and $4 \#$ rock samples tested under different imbibition time, the curves of the relationship between cumulative imbibition and imbibition time were gained, as shown in Figure 6. The rock samples had different pore volumes. Hence, to reduce the influence of pore volume difference on imbibition, we drew the curves of the relationship between imbibition per unit pore volume and imbibition time, as shown in Figure 7.

As shown in Figure 6, the imbibition of fracturing fluid at cores from different layers was divided into 2 stages. During the first stage, namely, the first 30 hours of imbibition, the cumulative imbibition surged with the increase of imbibition time, with the cumulative imbibition accounting for more than $70 \%$ of the total imbibition; in the second stage, that is, 30 hours after the imbibition, the increase of cumulative imbibition slowed down. At this stage, the imbibition at cores from different layers began to change in 2 patterns (Figures 6 and 7). In the first pattern, after 30 hours of imbibition, with the passage of time, the imbibition of fracturing fluid at the upper core of the reservoir hardly increased and basically remained stable (e.g., 3\# and 4\# rock samples). As shown in Table 1 and Figures 1-4, such core had high clay mineral content, low TOC content, and few pores with a diameter of larger than $10 \mathrm{~nm}$. Such core can quickly reach a state of saturation with its high clay mineral content and high imbibition velocity. In addition, due to hydration, shale expanded and the number of imbibition channels decreased. Therefore, after the imbibition lasted for a period of time, the increased amount of fracturing fluid remained basically stable. As for the second pattern, after 30 hours of imbibition, as time went by, the imbibition at the upper core of the reservoir continued to increase with the imbibition time, but quite slowly (e.g., 1\# and 2\# rock samples). Such core had high TOC content and a great number of pores with a diameter of larger than $10 \mathrm{~nm}$. Since the core had a relatively low clay mineral content, the fracturing fluid can permeate to the depth of the core and it takes a long time to reach a state of saturation. 


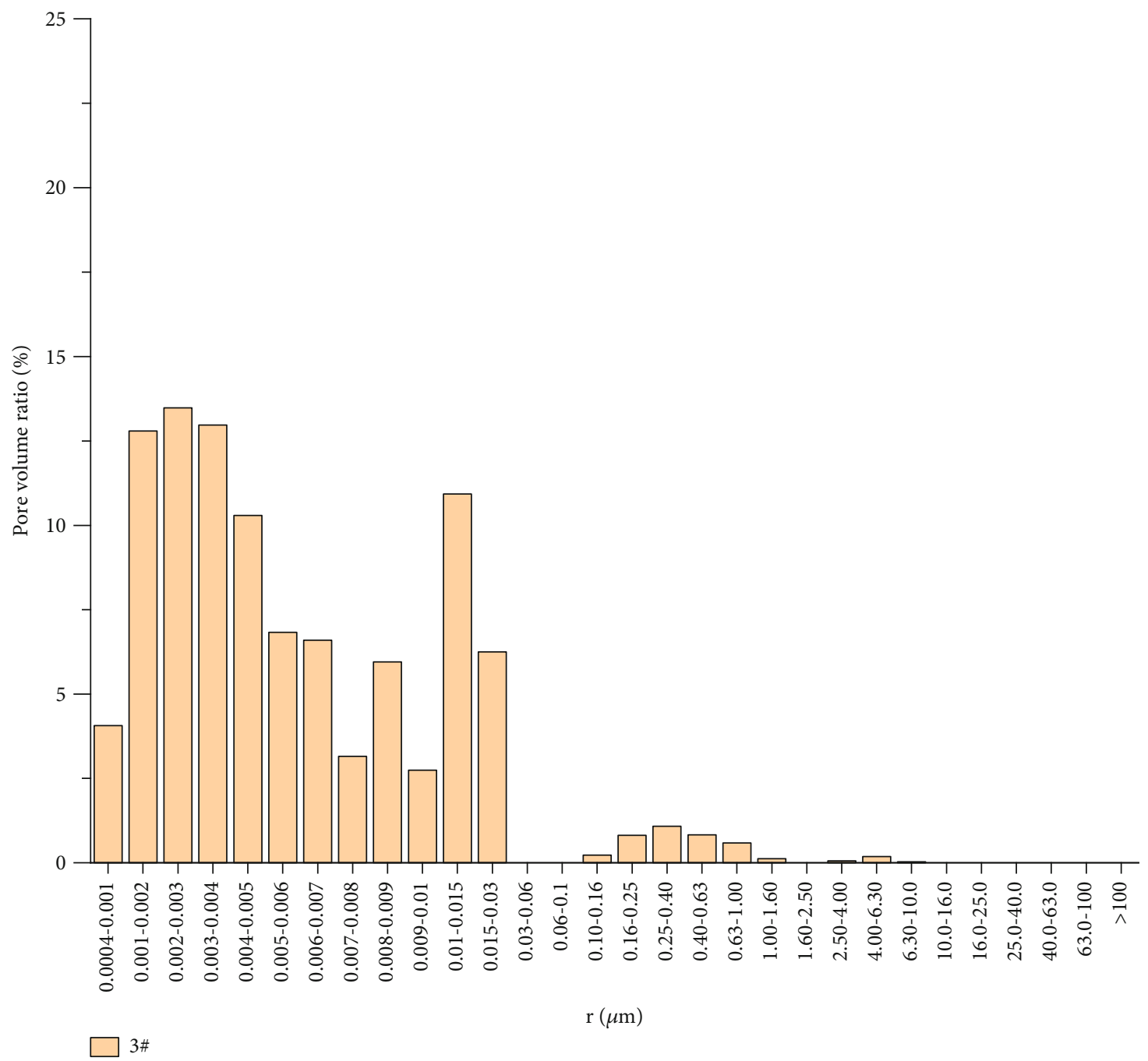

FIGURE 3: Distribution characteristics of pore structure of 3\# shale core sample.

Figure 7 shows the curves of the relationship between imbibition per unit pore volume and imbibition time. It can be seen from the figure that there are differences in imbibition per unit pore volume at cores from different layers. At 114 hours of imbibition, $4 \#$ core had the maximum imbibition per unit pore volume, $0.717 \mathrm{~g} / \mathrm{cm}^{3}$, accounting for $80 \%$ of the total pore volume of $4 \#$ core. The minimum imbibition per unit pore volume, $0.415 \mathrm{~g} / \mathrm{cm}^{3}$, was found at $2 \#$ core, taking up $64.43 \%$ of the total pore volume of this core. The imbibition per unit pore volume is closely related to core pore structure characteristics and clay mineral content. The higher the clay mineral content, the stronger the wettability of the reservoir and the greater the imbibition per unit pore volume. The higher the proportion of macropores, the greater the imbibition per unit pore volume.

\subsubsection{Characteristics of Imbibition Velocity}

(1) Variation law of imbibition velocity. Imbibition velocity is also one of the important features to understand the imbibition law of the reservoir. Based on the experimental results, we calculated the relationship between the average imbibition velocity at cores from different layers and imbibition time. Here, the average imbibition velocity refers to the total imbibition divided by the imbibition time. The average imbibition velocities at cores from different layers corresponding to different imbibition were calculated, respectively, and the curve relationship was drawn, as shown in Figure 8.

As shown in Figure 8, the curves indicating the relationship between average imbibition rate and imbibition time at cores from different layers are generally consistent, which accord with the relationship of power function. Besides, the average imbibition rate decreases rapidly at the initial stage, while after 30 hours of imbibition, the decrease of imbibition velocity slows down. By fitting the relationship between average imbibition velocity and imbibition time of 4 shale cores in Fuling shale gas reservoir, Equation (1) is obtained as follows:

$$
V=a t^{-n},
$$




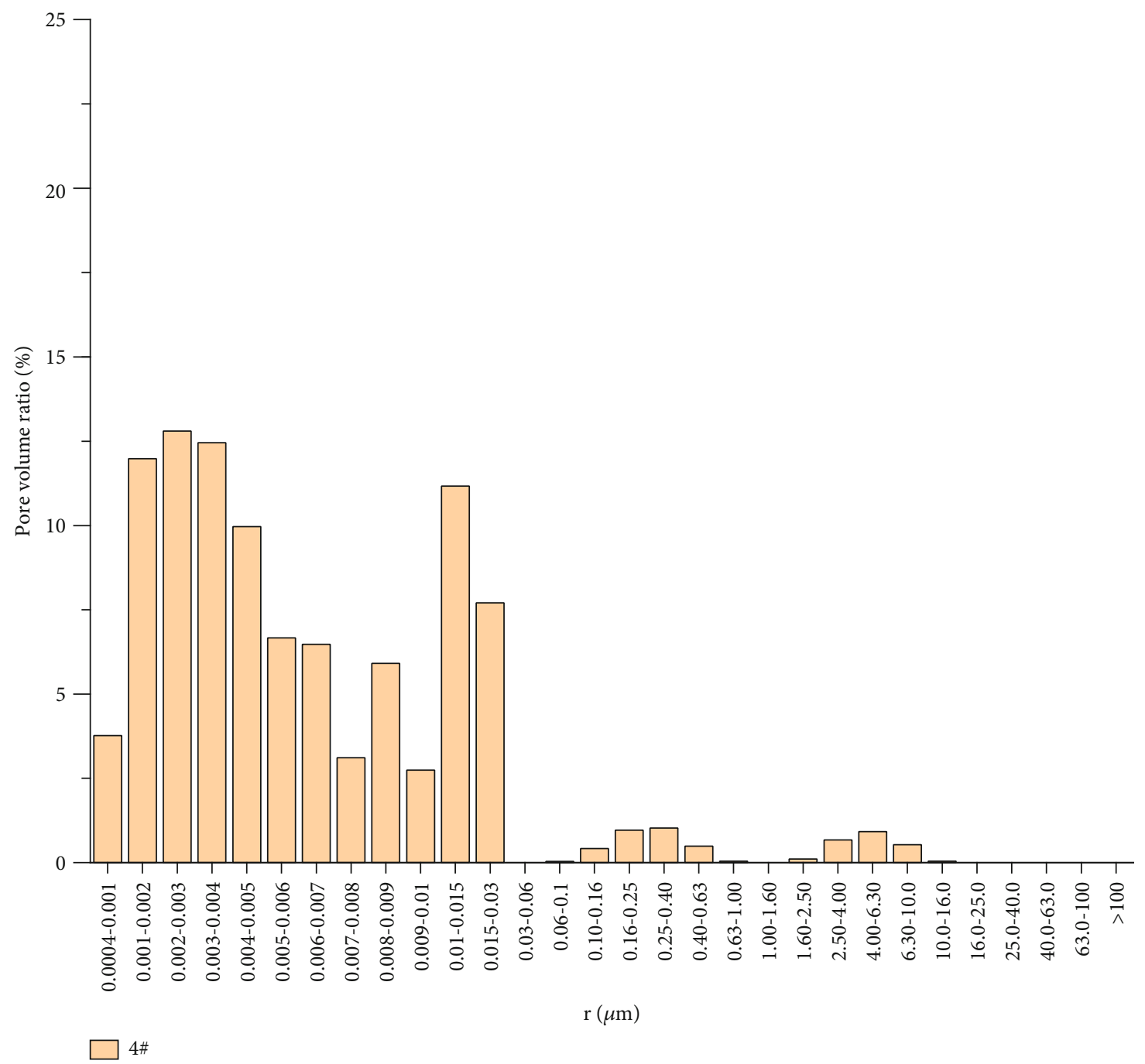

FIGURE 4: Distribution characteristics of pore structure of $4 \#$ shale core sample.

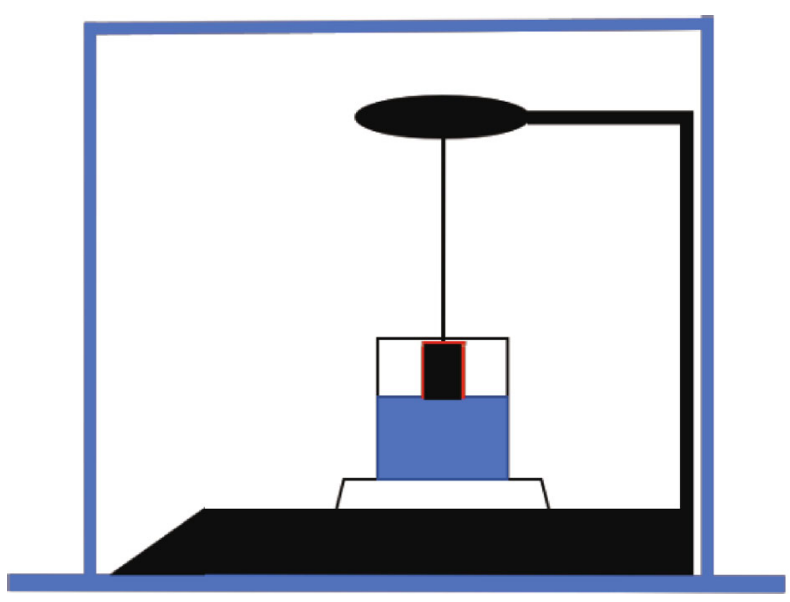

FIGURE 5: Imbibition experimental facility.

where $V$ denotes the average imbibition velocity $(\mathrm{g} / \mathrm{h}) ; t$ refers to the imbibition time; $a$ and $n$ represent the constants related to core characteristics.
However, with different core pore structure characteristics and mineral contents, though given the same imbibition time, the average imbibition velocity at cores from different layers is different. To analyze such difference, the relationship between the average imbibition rate and imbibition time of each rock sample was obtained as shown in Table 3 based on the imbibition data of different samples in Figure 8.

The average imbibition rate of each core fits well with its imbibition time, with the correlation coefficient $R^{2}$ being greater than 0.98 . The average imbibition velocities at both the initial and final phases of imbibition were calculated. The initial average imbibition velocity refers to the average imbibition velocity during the first 2 hours of imbibition, and the final imbibition velocity is the velocity when the imbibition has lasted for 114 hours. As shown in Table 3, there is a difference of 13-40 times between the initial and final average imbibition velocities of the 4 rock samples.

(2) Comparison with the Handy model. During the actual imbibition process, the core end face adsorbs the fracturing fluid. According to the Handy model [14], the variation 


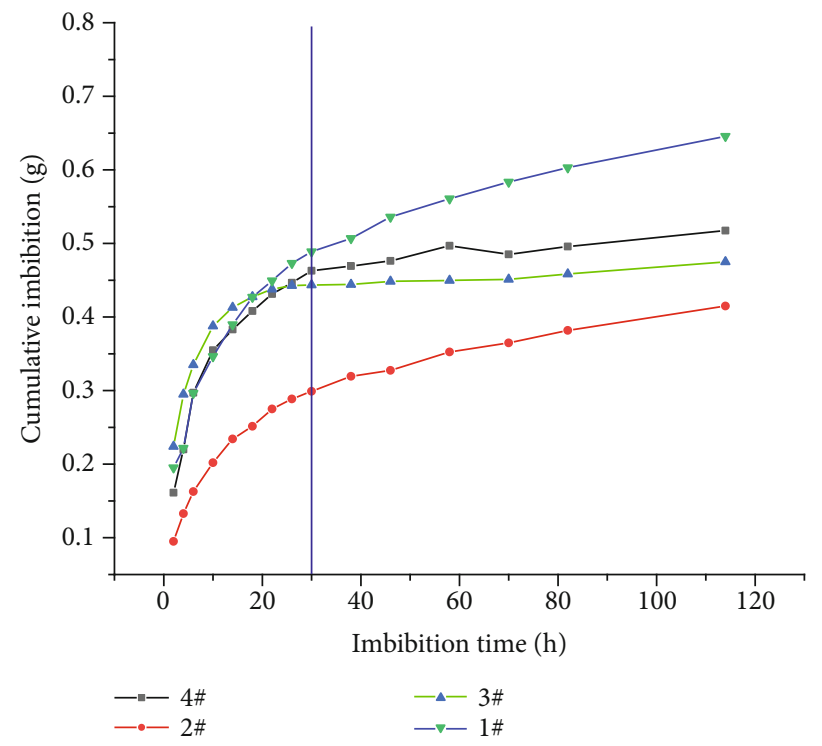

FIgURE 6: Curves of the relationship between cumulative imbibition and imbibition time.

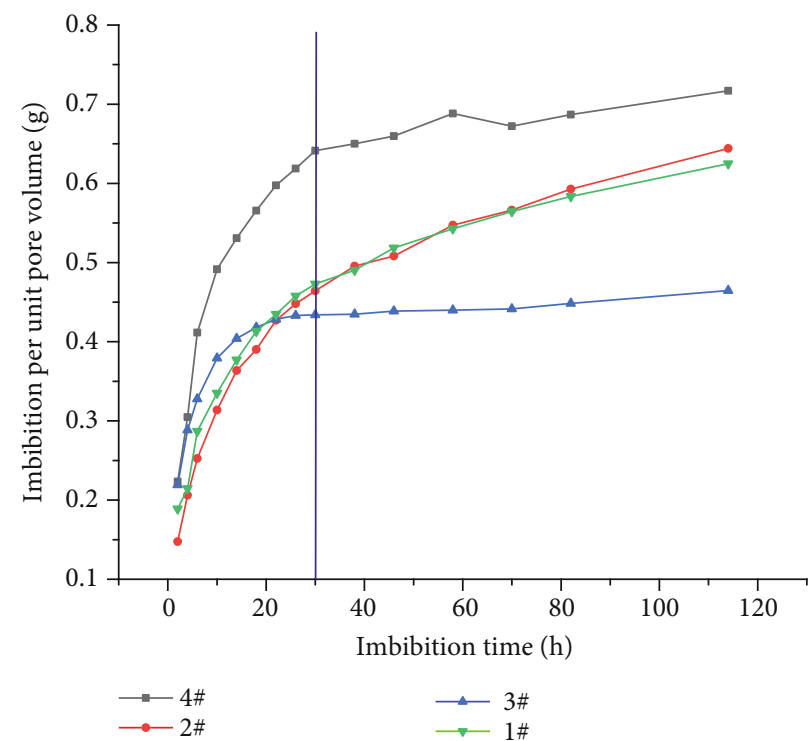

FIGURE 7: Curves of the relationship between imbibition per unit pore volume and imbibition time (imbibition per unit cross-sectional area).

pattern of the imbibition per unit area was calculated. Handy [14] established a model of spontaneous imbibition of water in saturated gas core:

$$
V_{\mathrm{imb}}^{2}=\frac{2 A_{C}^{2} P_{C} k \varnothing S_{w f} t}{\mu_{w}}
$$

Let imbibition rate $A_{i}$ be expressed as follows:

$$
A_{i}=\sqrt{\frac{2 P_{C} \phi k S_{w f}}{\mu_{w}}} .
$$

According to Equation (2), imbibition rate $A_{i}$ can be rep- resented by the slope of the curves of the relationship between water absorption per unit cross-sectional area and the square root of time:

$$
\frac{V_{\mathrm{imb}}}{A_{C}}=A_{i} \sqrt{t},
$$

where $V_{\text {imb }}$ denotes the imbibition fracturing fluid volume $\left(\mathrm{cm}^{3}\right), A_{C}$ stands for the cross-sectional area of the core $\left(\mathrm{cm}^{2}\right), A_{i}$ represents the imbibition rate $\left(\mathrm{cm} / \mathrm{h}^{0.5}\right), P_{C}$ denotes the capillary force $\left(P_{a}\right), \phi$ represents the porosity (decimal), $k$ denotes the permeability $(\mathrm{mD}), S_{w f}$ stands for the front water saturation (decimal), and $\mu_{w}$ represents the viscosity of water $(\mathrm{cP})$. 


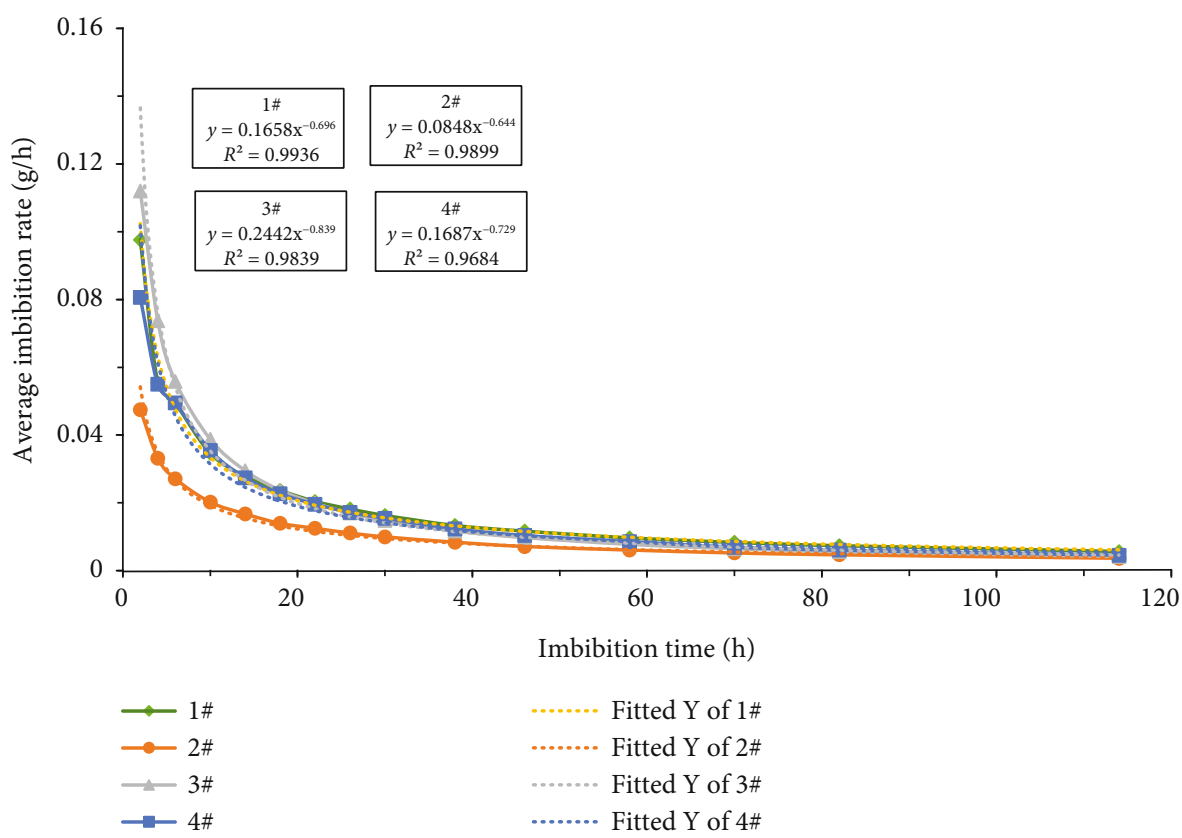

FIGURE 8: Curves of the relationship between average imbibition rate and imbibition time.

TABLE 3: Relationship between average imbibition velocity and imbibition time.

\begin{tabular}{lcccc}
\hline Samples & $\begin{array}{c}\text { Relationship between average imbibition velocity and } \\
\text { imbibition time }\end{array}$ & $R^{2}$ & $\begin{array}{c}\text { Initial average imbibition velocity } \\
(\mathrm{g} / \mathrm{h})\end{array}$ & $\begin{array}{c}\text { Final imbibition velocity } \\
(\mathrm{g} / \mathrm{h})\end{array}$ \\
\hline $1 \#$ & $V=0.15208 t^{-0.695}$ & 0.99 & 0.0801 & 0.0063 \\
$2 \#$ & $V=0.073 t^{-0.577}$ & 0.99 & 0.0976 & 0.0057 \\
$3 \#$ & $V=0.19 t^{-0.72}$ & 0.99 & 0.11205 & 0.0042 \\
$4 \#$ & $V=0.127 t^{-0.604}$ & 0.98 & 0.0806 & 0.0045 \\
\hline
\end{tabular}

Based on the experimental data of the 5 rock samples from different layers collected from the Fuling shale gas reservoir, we calculated the water absorption per unit cross-sectional area of each sample and drew the curves of the relationship between water absorption per unit crosssectional area and the square root of imbibition time, as shown in Figure 9.

Each curve in Figure 9 has 2 segments. The first segment is a straight line through the origin, which conforms to the linear characteristics of the Handy model. As for the second segment, with the increase of imbibition time, the imbibition proceeded at a slower pace. The slope of the second segment is smaller than that of the first segment. Therefore, for the imbibition process of shale core, the imbibition velocity of fracturing fluid in the shale gas well cannot be directly described and analyzed by the Handy equation. Though the prediction results obtained by the Handy model [14] are in good agreement with the experimental data of sandstone and limestone samples, the results cannot be directly used to calculate the imbibition velocity of fracturing fluid in shale gas wells.

Table 4 shows the concrete relationship between the absorption per unit cross-sectional area and the square root of imbibition time.
As indicated by the relationship between water absorption per unit cross-sectional area and the square root of imbibition time (Figure 10), the initial imbibition rate is correlated with the clay mineral content. If the clay mineral content is high, when the reservoir is undersaturated, the initial imbibition velocity of rock samples will be high. 3\#, $4 \#$, and $1 \#$ rock samples have relatively high imbibition velocity. Extracted from layers 8 and 9 of the WufengLongmaxi Formation, the clay mineral contents of $3 \#$ and $4 \#$ rock samples are $61.6 \%$ and $58.8 \%$, respectively, much higher than those of the other rock samples. Observable fractures were found in $1 \#$ rock sample (Table 1), which resulted in high initial imbibition velocity. It fully shows that when there are fractures, the initial imbibition will be accelerated. Hence, when fractures develop in the reservoir, the fracturing fluid enters the reservoir very fast, and the pressure of the fracturing construction curve drops rapidly. After 30 hours of fracturing, rock samples with low clay mineral content and large proportion of macropores (more than $50 \%$ in the case of this sample) have a high imbibition rate, with the cumulative imbibition continuing to increase. For instance, in the case of $1 \#$ and 2\# rock samples, such fracturing fluid can be absorbed into the deep reservoir to replace more shale gas. Besides, in the later production stage, the 


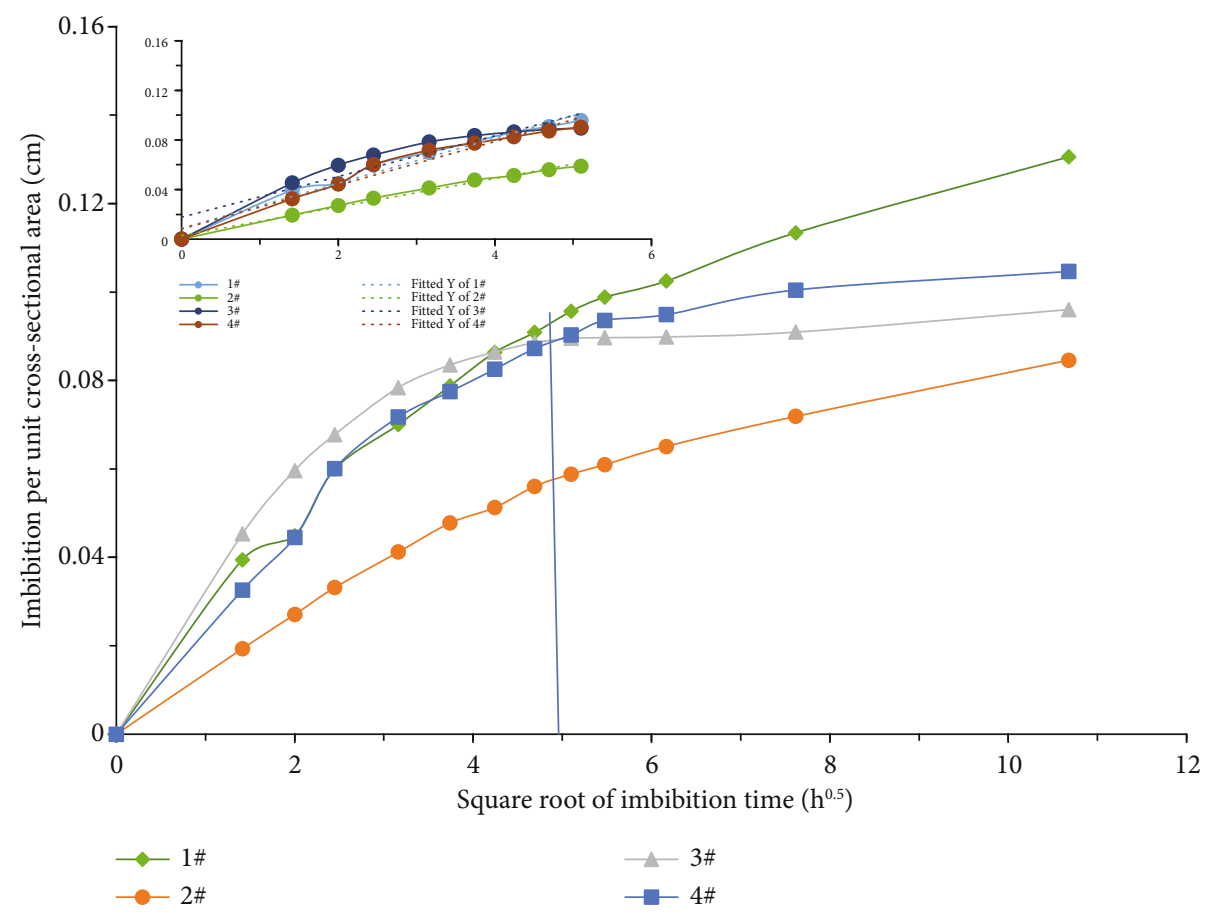

Figure 9: Curves of the relationship between water absorption per unit cross-sectional area and the square root of imbibition time.

TABLE 4: Fitting relationship of imbibition velocity in Handy model.

\begin{tabular}{lccc}
\hline Samples & Handy imbibition velocity $\left(\mathrm{cm} /\left(\mathrm{h}^{1 / 2}\right)\right)$ & Fitting equation & $R^{2}$ \\
\hline $1 \#$ & 0.0182 & $y=0.0182 x+0.0087$ & 0.97 \\
$2 \#$ & 0.0115 & $y=0.0115 x+0.0029$ & 0.99 \\
$3 \#$ & 0.0164 & $y=0.0164 x+0.00178$ & 0.87 \\
$4 \#$ & 0.0176 & $y=0.0176 x+0.0082$ & 0.95 \\
\hline
\end{tabular}

flowback rate is low, while the initial production is high. Moreover, according to the calculation results shown in Table 4, the imbibition rate at cores from layers 8 and 9 of the Longmaxi Formation in Fuling shale gas reservoir during the first stage can be $0.02 \mathrm{~cm} /\left(\mathrm{h}^{0.5}\right)$, and the imbibition rate at cores from layers 3 and 4 of the Longmaxi Formation during the first stage can be $0.01 \mathrm{~cm} /\left(\mathrm{h}^{0.5}\right)$.

(3) Calculation of cumulative imbibition and fracture area of fractured shale gas well. The cumulative imbibition and fracture area in the fractured shale gas well can be estimated based on the results of imbibition experiment. The experimental core samples represent different shale reservoirs. Table 3 shows the equation that calculates the changes of the average imbibition velocity when the fracturing fluid flows through shale core sections of different reservoirs (the cross-sectional area is $4.95 \mathrm{~cm}^{2}$ ). Based on the experimental results shown in Table 3, we selected the similar reservoirs represented by the experimental cores to calculate the cumulative imbibition, and the method is also applicable to the calculation of imbibition on the fracture surface of horizontal fractured wells.
Based on Equation (1) of calculating the average imbibition velocity, the equation of cumulative imbibition $W$ through the cross-sectional area of $4.95 \mathrm{~cm}^{2}$ was obtained by integral operation.

$$
W=a \int_{0}^{t} t t^{-n} d t=a \frac{t^{2-n}}{2-n},
$$

where $a$ and $n$ can be selected from Table 1 according to the characteristics of shale reservoir; $t$ denotes the fracturing construction time (h); $W$ is the cumulative imbibition through the section with a cross-sectional area of $4.95 \mathrm{~cm}^{2}$ (g).

The cumulative imbibition of fracturing fluid in shale gas wells with different fracturing time can be calculated based on Equation (5). The above analysis is based on the imbibition law obtained under the same conditions of core section, and the cumulative imbibition per unit area of shale can be obtained.

The fracture surface of the horizontal well was assumed to be $A\left(\mathrm{~m}^{2}\right)$, the total amount of injected fracturing fluid 


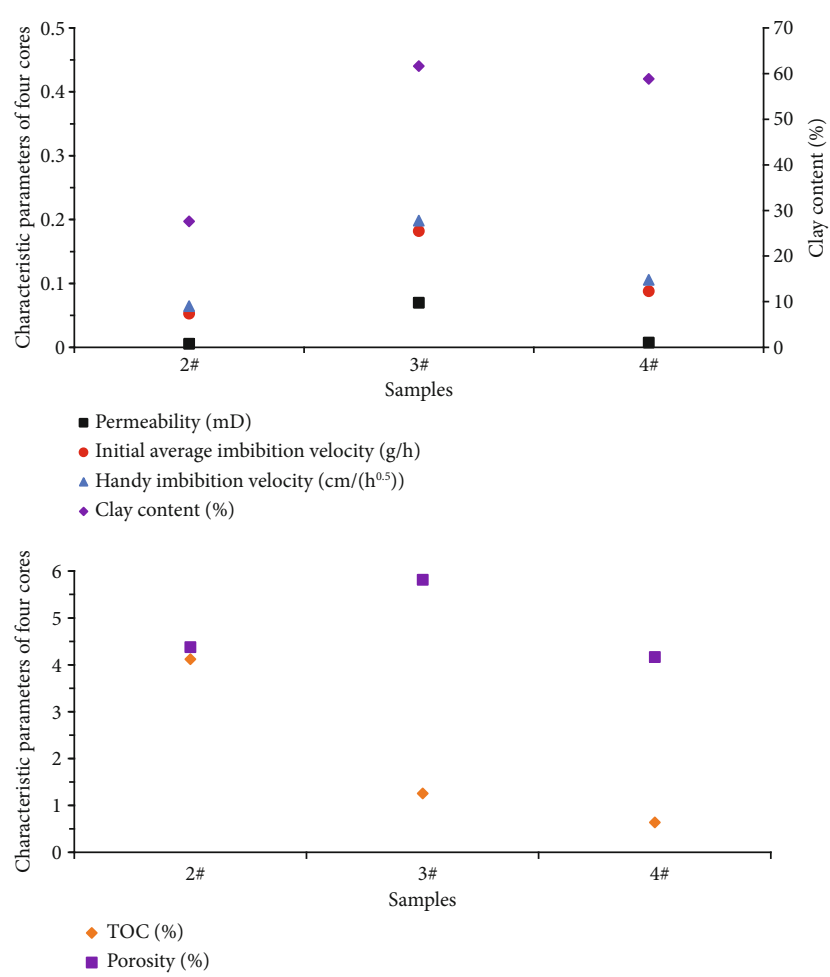

FIGURE 10: Relationship between characteristic parameters of different layers and imbibition velocity.

was supposed to be $Q_{i}\left(\mathrm{~m}^{3}\right)$, and the flowback volume of fracturing fluid was set as $Q_{p}\left(\mathrm{~m}^{3}\right)$. Since the fracturing fluid is mainly composed of water, the density was set as $1 \mathrm{~g} / \mathrm{cm}^{3}$. Therefore, $1 \mathrm{~m}^{3}$ of fracturing fluid was converted into $1000 \mathrm{~g}$ of water, and the equation for calculating cumulative imbibition is expressed as follows:

$$
Q_{i}-Q_{p}=\frac{A \times W \times 10^{-6}}{4.95 \times 10^{-4}}
$$

By substituting Equation (5) into Equation (6) and introducing the effective utilization rate $C$ of fracturing fluid, the equation of calculating the fracture surface of the shale gas horizontal well is obtained as follows:

$$
A=C \frac{495 \times\left(Q_{i}-Q_{p}\right) \times(2-n)}{a t^{2-n}},
$$

where $C$ is the effective utilization rate of the fracturing fluid (95-98\%) and the area of the fracture surface fractured by the horizontal well can be estimated based on Equation (7), so the fracturing scale can be analyzed.

\subsubsection{Main Factors Influencing Imbibition Characteristics.} Due to strong reservoir heterogeneity, small pore throat, high clay mineral content, and strong hydrophilicity of shale, different core characteristics will affect both the imbibition velocity and imbibition. The relationship between characteristic parameters of different layers and imbibition velocity of four cores is drawn, as shown in Figure 10.
Based on the variation of characteristic parameters of different cores, the relationship between characteristic parameters of different layers and imbibition velocity can be summarized as follows: (1) The higher the clay content, the higher the initial imbibition rate. (2) Porosity is well correlated with initial imbibition velocity, and the higher the porosity, the faster the initial imbibition. (3) There is no good correlation between cumulative imbibition and pore volume, which indicates that cumulative imbibition is not merely determined by pore volume, but is closely related to pore structure characteristics and composition of shale minerals.

\section{Discussion}

The rock samples used in the imbibition experiment were extracted from the first section of Wufeng-Longmaxi Formation in Phase-I Production and Construction Area in Jiaoshiba block of Fuling shale gas reservoir in China. The specific parameters of the cores were measured by standard instruments to ensure the reliability of the experimental results.

Based on the imbibition data of cores from different layers, the average imbibition velocity of shale lives up to the diminishing law of power function. The imbibition was divided into two stages. During the first stage, namely, the first 30 hours of imbibition, the imbibition velocity was high, with the cumulative imbibition accounting for more than $72 \%$ of the total imbibition. During the second stage, the imbibition velocity remained stable or slightly increased. Because of the strong surface adsorption, the imbibition velocity was high at the beginning. The average imbibition velocity increased during the later period because there was a high proportion (greater than 50\%) of macropore throat with a diameter of over $10 \mathrm{~nm}$ in the cores. The average imbibition rate and imbibition time of shale reservoir core conform to the power function relationship which runs throughout the whole imbibition process. However, the Handy model is not suitable to characterize the imbibition characteristics of shale core. According to the Handy model, the square root of the imbibition time is linearly related to the imbibition per unit area, but the actual relationship is divided into two segments. The power function relationship makes it convenient for us to calculate and analyze the actual imbibition velocity and cumulative imbibition. Nevertheless, to calculate the actual imbibition velocity and cumulative imbibition of the shale gas reservoir using the power function, relevant parameters should be obtained by experiment, which brings inconvenience to later applications. It is suggested that imbibition experiments should be carried out based on different shale gas core characteristics so as to obtain the template formula of calculating the declining imbibition representing different types of cores, that is, different power function parameter values. In this way, the imbibition of different shale gas reservoirs can be directly calculated using the template formula.

Based on the variation pattern of the average imbibition velocity, we obtained the formula of calculating cumulative imbibition and estimating the fracture surface of shale gas horizontal well, which helped to gain the cumulative imbibition per unit area of the shale gas reservoir. The estimation 
TABLE 5: Estimation of fracturing scale.

\begin{tabular}{|c|c|c|c|c|c|c|c|}
\hline Layer & $\begin{array}{l}\text { Fracturing } \\
\quad \text { fluid } \\
\text { utilization(\%) }\end{array}$ & $\begin{array}{l}\text { Fracturing fluid } \\
\text { injection volume } \\
\qquad\left(\mathrm{m}^{3}\right)\end{array}$ & $\begin{array}{c}\text { Volume of } \\
\text { fracturing fluid } \\
\text { flowback }\left(\mathrm{m}^{3}\right)\end{array}$ & $\begin{array}{l}\text { Coefficient } a \\
\text { in Equation } \\
\text { (1) }\end{array}$ & $\begin{array}{l}\text { Coefficient } n \\
\text { in Equation } \\
(1)\end{array}$ & $\begin{array}{l}\text { Time of fracturing fluid } \\
\text { entry into the reservoir } \\
\text { (h) }\end{array}$ & $\begin{array}{l}\text { Fracturing } \\
\text { cracks area } \\
\left(\mathrm{m}^{3}\right)\end{array}$ \\
\hline $\begin{array}{l}\text { The } \\
\text { lower } \\
\text { layer }\end{array}$ & 0.98 & 45000 & 2250 & 0.152 & 0.69 & 114 & 474957 \\
\hline $\begin{array}{l}\text { The } \\
\text { upper } \\
\text { layer }\end{array}$ & 0.98 & 45000 & 2250 & 0.19 & 0.72 & 114 & 374189 \\
\hline
\end{tabular}

of the fracture surface can be applied to analyze the scale and complexity of fracturing. Nonetheless, in the actual fracturing process, apart from imbibition, the injection of fracturing fluid still includes the inflow, leakage, and loss of differential pressure. Hence, it is critical to determine the value of $C$ in Equation (7).

According to the calculation results in Table 5, the fracturing scale of the lower reservoirs represented by $1 \#$ core is larger than that of the upper reservoirs with $3 \#$ core as the representative. In the Fuling shale gas well, the lower reservoirs have a larger fracturing scale and a greater output than the upper reservoirs, which is consistent with the prediction results.

The imbibition time was set to be 114 hours in the experiment. In terms of the production in the mine field, the shutin time after shale gas horizontal well fracturing can be regarded as the imbibition time. However, based on the analysis of the imbibition experimental results, the imbibition began to slow down after 30 hours and remained basically stable after 60 hours. Therefore, 3 days is enough as the shut-in time after shale gas horizontal well fracturing.

\section{Conclusion}

Due to the heterogeneity, nanopore, high clay mineral content, and strong hydrophilicity of shale gas reservoir, its imbibition process is greatly different from that of conventional sandstone. In this study, abundant experiments were carried out on the shale gas from different layers and with different characteristics in the Fuling shale gas reservoir to obtain the following conclusions.

(1) Shale imbibition can be divided into two stages separated by 30 hours. The initial imbibition was fast, with the cumulative imbibition in the first 30 hours accounting for $72-95 \%$ of the total imbibition. After 30 hours, the imbibition velocity was substantially reduced. When the proportion of pore throat with a diameter of larger than $10 \mathrm{~nm}$ in the core is less than $20 \%$, the cumulative imbibition curve is stable; when such a proportion is greater than $20 \%$, the cumulative imbibition curve presents an upturn

(2) Throughout the imbibition process, there is a power function relationship between the average imbibition velocity and imbibition time. This result can be used to preliminarily estimate the cumulative imbibition per unit area and the fracture surface of the fractured well. The initial imbibition rate of Fuling shale gas reservoir is within the range of $0.05-0.11 \mathrm{~g} / \mathrm{h}$

(3) The Handy model is unable to describe the entire process of shale reservoir imbibition, and the imbibition law of shale reservoirs cannot be solely based on the Handy model. The Handy model is applicable to estimate the imbibition during the first 30 hours of imbibition, and a new model needs to be established in the later stage. The imbibition rate at cores from layers 8 and 9 of the Longmaxi Formation in Fuling shale gas reservoir during the first stage can be 0.02 $\mathrm{cm} /\left(\mathrm{h}^{0.5}\right)$, and the imbibition rate at cores from layers 3 and 4 of the Longmaxi Formation during the first stage can be $0.01 \mathrm{~cm} /\left(\mathrm{h}^{0.5}\right)$

(4) Cumulative imbibition has nothing to do with core volume, but is related to pore throat characteristics and clay content. The higher the clay mineral content and the higher the proportion of macropore throat, the larger the cumulative imbibition. The imbibition of fracturing fluid is based on multiple actions, i.e., core surface adsorption, pore throat diffusion, and capillary force, on the core

\section{Data Availability}

The data used to support the findings of this study are available from the corresponding author upon request.

\section{Conflicts of Interest}

The authors declare that there are no conflicts of interest regarding the publication of this article.

\section{Acknowledgments}

This publication is based on work supported by the National Natural Science Foundation of China, under grant (51804039).

\section{References}

[1] D. Dong, S. Gao, H. Jinliang, G. Quanzhong, W. Shufang, and W. Yuman, "A discussion on the shale gas exploration \& development prospect in the Sichuan Basin," Natural Gas Industry, vol. 34, no. 12, pp. 1-15, 2014. 
[2] R. M. Slatt and N. R. O'Brien, "Pore types in the Barnett and Woodford gas shales: contribution to understanding gas storage and migration pathways in fine-grained rocks," AAPG Bulletin, vol. 95, no. 12, pp. 2017-2030, 2011.

[3] H. Chengzu and H. Wencai, "Discussion on water locking effect and reservoir damage," Natural Gas Industry, vol. 14, no. 6, pp. 36-38, 1994.

[4] G. S. Penny, T. A. Dobkins, and J. T. Pursley, "Field study of completion fluids to enhance gas production in the Barnett shale," in SPE Gas Technology Symposium, Calgary, Alberta, Canada, 2006.

[5] J. B. Sherman and S. A. Holditch, "Effect of injected fracture fluids and operating procedures on ultimate gas recovery," in SPE Gas Technology Symposium, Houston, Texas, 1991.

[6] B. Bazin, Y. Peysson, F. Lamy, F. Martin, E. Aubry, and C. Chapuis, "In situ water-blocking measurements and interpretation related to fracturing operations in tight gas reservoirs," SPE Production \& Operations, vol. 25, no. 4, pp. 431-437, 2010.

[7] Y. Cheng, "Impact of water dynamics in fractures on the performance of hydraulically fractured wells in gas shale reservoirs society of petroleum engineers," in SPE International Symposium and Exhibition on Formation Damage Control, Lafayette, Louisiana, USA, January 2010.

[8] Y. Lijun, K. Yili, C. Zhangxin, C. Qiang, and Y. Bin, "Wellbore instability in shale gas wells drilled by oil-based fluids," International Journal of Rock Mechanics \& Mining Sciences, vol. 72, pp. 294-299, 2014.

[9] Z. Shicheng, G. Tiankui, and Z. Tong, "Fracture propagation mechanism experiment of hydraulic fracturing in natural shale," Acta Petrolei Sinica, vol. 35, no. 3, pp. 496-503, 2014.

[10] G. Xiaozhe and Z. Changsha, "The trilinear seepage model for fractured horizontal well in shale gas reservoir," Journal of Southwest Petroleum University (Science \& Technology Edition), vol. 38, no. 2, pp. 86-94, 2016.

[11] E. Ghanbari and H. Dehghanpour, "Impact of rock fabric on water imbibition and salt diffusion in gas shales," International Journal of Coal Geology, vol. 138, no. 15, pp. 55-67, 2015.

[12] E. W. Washburn, “The dynamics of capillary flow," Physical Review, vol. 17, no. 3, pp. 273-283, 1921.

[13] C. C. Mattax and J. R. Kyte, "Imbibition oil recovery from fractured water-drive reservoir," SPE Journal, vol. 2, no. 2, pp. 177-184, 1962.

[14] L. L. Handy, "Determination of effective capillary pressures for porous media from imbibition data," Transactions of the AIME, vol. 219, no. 1, pp. 75-80, 1960.

[15] A. Gupta and F. Civan, "An improved model for laboratory measurement of matrix to fracture transfer function parameters in immiscible displacement," in SPE Annual Technical Conference and Exhibition, New Orleans, Louisiana, 1994.

[16] K. W. Li and R. N. Horne, "Generalized scaling approach for spontaneous imbibition: an analytical model," SPE Reservoir Evaluation \& Engineering, vol. 9, no. 3, pp. 251-258, 2006.

[17] G. Mason, H. Fischer, N. Morrow, and D. W. Ruth, "Correlation for the effect of fluid viscosities on counter-current spontaneous imbibition," Journal of Petroleum Science and Engineering, vol. 72, no. 1-2, pp. 195-205, 2010.

[18] IUPAC, "Physical chemistry division commission on colloid and surface chemistry, subcommittee on characterization of porous solids: recommendations for the characterization of porous solids," Pure and Applied Chemistry, vol. 66, no. 8, pp. 1739-1758, 1994. 